\title{
NHŨ்NG ĐẶC TRƯNG TRONG SÁNG TÁC TRUYỆN NGĂN CỦA NHÀ VĂN AI CẬP YUSUF IDRIS
}

\author{
Nguyễn Thị Hồng Hạnh* \\ Bộ môn Ngôn ngũu và Văn hoá Ả rập, Truờng Đại học Ngoại ngũu, ĐHQGHN, \\ Phạm Văn Đồng, Cầu Giấy, Hà Nội, Việt Nam \\ Nhận bài ngày 26 tháng 09 năm 2017 \\ Chỉnh sửa ngày 19 tháng 01 năm 2018; Chấp nhận đăng ngày 22 tháng 01 năm 2018
}

Tóm tắt: Nhà văn Yusuf Idris (1927-1991) được coi là một trong những người tiên phong đặt nền móng cho sự phát triển truyện ngắn hiện đại ở Ai Cập nói riêng và Ả rập nói chung. Những tác phẩm của ông đã mở ra cánh cửa mới cho văn đàn đất nước, ảnh hưởng đến nhiều tác giả trẻ ở thế hệ sau. Vì vậy, việc nghiên cứu những đặc trưng trong các sáng tác truyện ngắn của tác giả này đóng vai trò quan trọng trong quá trình tìm hiểu dòng chảy phát triển văn học hiện đại ở khu vực Ả rập. Trong giới hạn cho phép, bài viết này sẽ tập trung khảo sát bốn đặc trưng chính, nổi bật trong các tác phẩm truyện ngắn của nhà văn Yusuf Idris, đó là: mâu thuẫn giữa tầng lớp giàu - nghèo, nông thôn - đô thị; biểu tượng im lặng; biểu tượng không gian khép kín và sự sử dụng sinh ngữ Ả rập Ai Cập.

Tù̀ khoá: Yusuf Idris, nông thôn, truyện ngắn, Ai Cập, biểu tượng

\section{Giới thiệu tác giả Yusuf Idris}

Yusuf Idris sinh ngày 19 tháng 5 năm 1927 tại al-Bayrum (Faqous), Ai Cập. Từ năm 1945 đến năm 1951, ông học chuyên ngành Y tại Đại học Cairo. Trong khoảng thời gian sinh viên đầy nhiệt huyết của tuổi trẻ, ông đã viết những tác phẩm đầu tiên trong đời. Ngay sau khi nhận tấm bằng tốt nghiệp năm 1952, ông trở thành thanh tra y tế tại Sở Y tế. Giữa những năm 1960, sau gần một thập kỷ cống hiến cho ngành $Y$, ông rũ bỏ công việc và hoàn toàn tập trung vào sự nghiệp văn chương và để lại những dấu ấn không thể phai mờ trên văn đàn Ai Cập nói riêng và Ả rập nói chung.

Trong thời đại của những trí tuệ và tài năng vĩ đại đã đưa Ai Cập đến thời kỳ Phục hưng văn học giữa năm 1880 và 1960, Yusuf Idris được thừa nhận rộng rãi là bậc thầy của truyện ngắn Ai Cập. Sử dụng một phong cách ngắn gọn, giàu năng lượng mà cảm giác gắn liền với trí tưởng tượng và trí tuệ, tài năng của ông đã bùng nổ với sự gia tăng số lượng tác phẩm sau cuộc Cách mạng 1952(1). Những câu

* ĐT.: 84-911538738

Email: honghanh.nguyen.89@icloud.com chuyện của ông ngay từ đầu đã mang tính đối đầu và khiêu khích, được thể hiện rõ ràng từ cam kết vững chắc của ông đối với các hoạt động chính trị. Việc kết hợp các chủ đề chính trị và văn hoá của ông khiến một số nhà phê bình xem những câu chuyện của ông như sự phản chiếu khôn ngoan của nhà nước Ai Cập trong quá trình chuyển mình trở thành một quốc gia hiện đại độc lập. Các nhà bình luận đã ca ngợi những câu chuyện tuyệt vời của ông về việc sử dụng huyền thoại và tục ngữ, thành ngữ dân gian. Ông được coi là một nhà văn tiên phong đề cập đến các chủ đề nhạy cảm như tình dục đồng giới, chứng liệt dương và nguy cơ của chủ nghĩa tôn giáo cực đoan. Những nỗ lực của nhà văn đóng vai trò quan trọng và có ảnh hưởng mạnh mẽ trong nền văn học Ả rập và Ai Cập.

\footnotetext{
${ }^{1}$ Cách mạng 1952: Cuộc đảo chính quân sự lật đổ vị vua Ai Cập cuối cùng - vua Farouk, người bị chỉ trích vì tình trạng tham nhũng nặng nề của chính phủ cũng như thất bại trong cuộc chiến Ả rập - Israel. Tướng Mahuammd Naguib, người chỉ huy đảo chính được trao quyền trở thành tổng thống đầu tiên của nước Cộng hoà Ả rập Ai Cập, kết thúc chế độ quân chủ chuyên chế ở nước này.
} 


\section{Những đặc trưng trong sáng tác truyện ngắn của Yusuf Idris}

2.1. Mâu thuẫn và khoảng cách giữa tầng lớp giàu - nghèo, nông thôn - đô thị trong xã họi Ai Cập

Khoảng đầu những năm 1940, Ả rập chứng kiến nhiều biến động xã hội và chính trị như Hiệp ước Độc lập ở Ai Cập (1936), cuộc nổi dậy ở Palestine, Iraq cùng với những nỗ lực trục xuất người Pháp ra khỏi lãnh thổ Syria, Lebanon. Sự tức giận, sục sôi của xã hội, những vấn đề tôn giáo bức bối đã được phản ánh trong những truyện ngắn được sáng tác trong giai đoạn này. Taha Husayn là người đã tiên phong trong lĩnh vực truyện ngắn bằng cách đặt ra một lối viết mới về người nghèo. Những tác phẩm của ông nói về bối cảnh cuộc đời đau khổ, hoạn nạn của tầng lớp người dễ bị tổn thương trong xã hội Ai Cập đã góp phần tạo ra động lực, mở một hướng đi văn chương mới cho văn đàn trẻ của nước này, nhằm thể hiện sự tức giận, phản đối về xã hội và chính trị. Tuy nhiên, đây vẫn chỉ là những bước manh nha đầu tiên, ông vẫn chưa thoát ra khỏi cái bóng của nền văn học lãng mạn trước đó.

Chỉ đến khi những tác phẩm của Yusuf Idris xuất hiện, phong trào thoát ly lãng mạn mới thực sự trỗi dậy mạnh mẽ, hướng tới văn học hiện thực chủ nghĩa, đặc biệt là trong lĩnh vực truyện ngắn. Có thể nói tài năng của Yusuf Idris đã làm lu mờ lớp nhà văn đương thời vì những sáng tác của ông không chỉ phong phú về hình thức, đa dạng về chủ đề mà còn liên tục phát triển. Sinh ra trong một gia đình giàu có nhưng từ nhỏ Yusuf Idris đã phải sống xa cha mẹ ở vùng quê vì đặc thù công việc của người cha. Những trải nghiệm của thời thơ ấu về sự lam lũ nơi thôn quê Ai Cập đã mang lại cho ông nhận thức sâu sắc về nỗi đau khổ và cái nghèo đói.

Khung cảnh làng quê trong truyện của ông không mang vẻ lãng mạn, nên tho nhu trong thế giới tiểu thuyết của tác giả
Muhammad Husayn Haykal. Trái lại, ông khắc hoạ một cách chân thực nhũng mảnh đời bấp bênh, chống chọi lại con phong ba bão táp của số phận.

Truyện ngắn Mishwar (Một chuyến đi) kể về một cảnh sát địa phương bắt người phụ nữ điên đưa lên bệnh viện tâm thần ở Cairo đã phản ánh sự việc từ cả hai góc nhìn. Đó là góc nhìn mang thái độ, suy nghĩ của những người nông thôn đối với đô thị và góc nhìn thờ ơ tù̀ phía các nhân viên cảnh sát ở đô thị đối với hoàn cảnh của viên cảnh sát địa phương.

Cuộc sống khốn cùng của người dân quê Ai Cập còn được nhìn nhận theo một khía cạnh rất khác lạ, mới mé.

Điều này thể hiện rõ nhất trong câu chuyện Arkhas Layyali (Những đêm rẻ nhất). Tác phẩm tưởng chừng như là một câu chuyện bâng quơ về anh chàng ở nông thôn nghèo nào đó. Nhưng càng đọc, độc giả càng thấy sự chua xót trước cái vòng luẩn quẩn của cuộc sống không lối thoát của người nông dân Ai Cập cùng khổ. Mở đầu truyện, anh chàng Abdel Kerim sau buổi cầu nguyện, trên đường vào thị trấn, vừa đi vừa tuôn một tràng xối xả nguyền rủa cha mẹ, ông bà, tổ tiên của những đứa trẻ xa lạ mà anh ta vô tình nhìn thấy. Rồi anh ta lại tự nhủ thầm, an ủi bản thân rằng một nửa trong số những đứa trẻ đó sẽ chết vì đói, số còn lại sẽ chết vì bệnh tả. Dần dần, lý do cho sự phẫn uất khó hiểu đó dần được hé lộ. Anh ta có ác cảm đối với tất cả trẻ em vì anh ta là cha của sáu đứa trẻ lúc nào cũng thiếu ăn, thiếu mặc. Rồi anh suy nghĩ về việc có nên đi đến quán cà phê trong thị trấn để uống một cốc cà phê hay hút điếu thuốc lá trong khi nghe đài radio và xem những người đàn ông khá giả chơi bài. Tuy nhiên, anh nhận ra là mình không có đủ tiền để đến đó. Suy nghĩ hồi lâu về những việc gì có thể làm để thoát khỏi tâm trạng chán nản, cuối cùng anh ta quyết định trở về nhà với người vợ "nằm như một cái túi ngô với sáu đứa con xung quanh như một đàn cún". 
Anh ngồi xuống cạnh cô, lúng túng với đống quần áo của mình, và cô bị đánh thức dậy, "chuẩn bị cho những gì sắp xảy ra" - hình thức giải trí rẻ nhất của anh. Và như một kết quả định sẵn, ít lâu sau đó, đứa trẻ thứ bảy ra đời, đặt thêm gánh nặng lên đôi vai của anh. Thậm chí, nhiều năm, tháng sau, những đứa trẻ khác cũng nối đuôi nhau đến với gia đình anh. Có thể thấy, những người đàn ông nghèo trong xã hội Ai Cập bị mắc kẹt trong cái bẫy: họ không có đủ tiền để uống một cốc trà có giá còn rẻ hơn những biện pháp tránh thai nhưng họ vẫn phải có niềm vui, hình thức giải trí trong cuộc sống.

Độc giả thường khó tìm thấy một cái kết có hậu trong nhiều truyện ngắn của Yusuf Idris, thay vào đó, chì là nhũng bưc tranh chân thưcc nhất về nông thôn Ai Cập, văng vẳng trong không gian là tiếng khóc, phản ánh sư thật một cách trục tiếp nhất, đơn giản nhất.

Ví dụ chúng ta sẽ bắt gặp một bé gái trong câu chuyện Nazra (Một cái nhìn) đang cố hết sức giữ cái khay đồ ăn ở trên đầu tránh khỏi bị rơi. Cô bé băng qua đường khiến cho cái khay dường như muốn trượt xuống lần nữa. Bỗng cô bé dừng lại chỉ để nhìn lũ trẻ đang chơi bóng gần đó, nhưng nhanh chóng lại chìm vào thất vọng vì em phải tiếp tục làm việc. Hay như một thầy giáo vừa phải mang trên vai gánh nặng về gia đình, vừa phải đối mặt với một nhóm học sinh bất trị khi ở trường trong al-Shahada (Chúng chì).

Trong thời gian Yusuf Idris làm việc ở Cairo với tư cách là bác sĩ, ông đã quan sát một cách sâu sắc hơn về bản chất con người trong xã hội. Ông không cảm thấy xa lạ mà rất quen thuộc với cuộc sống trong các khu nhà ổ chuột, trong các ngõ hẻm quanh co giữa thành phố lớn. "Yếu tố này làm sắc bén và phong phú thêm nhận thức của Idris về những điều ngớ ngẩn và mâu thuẫn trong một xã hội có ý thức về sự phân tầng lớp, do đó, ông thường "bắt" được những khoảnh khắc rất thật trong cuộc sống Ai Cập” (Somekh, 1976).
Yusuf Idris đã thẳng thắn chi trich, mia mai thái độ vô tâm của nhũng người thuộc tầng lớp giàu có, quyền lục đối với nhũng người có địa vị thấp mà ho sủ dụng rồi sau đó vứt bỏ.

Qa al-Madina (Đáy của thành phố) là một ví dụ điển hình cho lối viết này và được đánh giá là một trong những tác phẩm thành công nhất của nhà văn. Đây là một câu chuyện đầy tính mỉa mai xoay quanh vị thẩm phán Abd Allah trẻ tuổi đánh mất đồng hồ và nghi ngờ cô hầu gái đã đánh cắp nó. Câu chuyện phức tạp hơn khi mối quan hệ giữa vị thẩm phán và cô hầu gái được hé lộ. Hai người không chỉ dừng lại ở mức độ ông chủ và người làm thuê mà còn có cả những quan hệ xác thịt. Abd Allah được miêu tả là người có quyền thế và giàu có, giữ địa vị cao trong xã hội. Cương vị nghề nghiệp cho phép anh phán xét hành động của mọi tầng lớp trong xã hội từ giàu đến nghèo. Anh hài lòng với cuộc sống của mình và rất ít khi rời khỏi khu phố xanh tươi ở Cairo nơi anh sống. Tuy nhiên viễn cảnh đến tận nơi cô hầu gái sống - khu vực nghèo nhất của thành phố để mặt đối mặt với tội phạm khiến anh trở nên say sưa, sung sướng. Anh hoan hỷ khi có cơ hội chỉ ra đích danh tội phạm mà theo anh đã đe doạ đến lý tưởng mà anh dùng nó làm biện minh cho cuộc sống của mình. Với kinh nghiệm nghề nghiệp, không khó đối với Abd Allah để đạp đổ sự cứng đầu, tỏ ra vô tội của cô gái nghèo, không được đi học và nhanh chóng phát hiện ra nơi cất giấu đồng hồ của mình. Lại một câu chuyện với cái kết không có hậu nữa dưới ngòi bút của Yusuf Idris. Người ta như thấy những người nghèo như cô hầu gái sẽ không thể nào có một tương lai tốt đẹp hơn nếu vẫn sống trong một xã hội đầy bất công, thờ or, đạo đức giả như hiện tại.

Qua cuộc hành trình của vị thẩm phán đáng kính đến nhà cô hầu gái, tác giả đã dùng ngòi bút điêu luyện phác hoạ toàn bộ bức 
tranh Cairo tù nơi giàu nhất đến nơi nghèo nhất, nhấn mạh sự khác biệt giữa hai tầng lớp xã hội.

Chuyến đi của vị thẩm phán bắt đầu từ khu phố hiện đại, giàu có, thoáng đãng nơi ông sống. Chiếc xe chở anh băng qua những quận khác nghèo hơn, bầu không khí cũng trở nên khó thở hơn, cả về mặt sinh lý và tâm lý. Các khu phố càng lúc càng đông người, hẹp dần lại đến nỗi ông khó có thể di chuyển được bằng ô tô. Người dân sống tại đây cũng nghèo hơn. Những cửa hàng, ngôi nhà nhỏ hơn, bẩn thỉu hơn. Cho đến khi đoàn người của anh thẩm phán đến "Đáy của thành phố" nơi mà cô hầu gái sống, họ thấy những ngôi nhà dựa vào nhau mà đứng xiêu vẹo. Những đứa trẻ thì chơi trong đống rác, phụ nữ ngồi tán dóc ở dưới các mái hiên và ruồi bay khắp nơi. Có thể thấy mỗi bước tiến xa hơn trong chặng đường của Abd Allah là một lớp vỏ bao bọc cuộc sống êm đẹp mà anh tạo ra từ trước đến nay bị lột trần. Mọi thứ trở dần chuyến biến, trở nên xấu xí, bẩn thỉu hơn, bao gồm cả người và cảnh vật. Nhưng, thay vì cảm thông cho những người nghèo khổ hơn mình, Abd Allah càng lúc càng trở nên bực dọc vì khung cảnh đáng ghét xung quanh.

Có thể thấy tác giả đã lựa chọn những chi tiết vô cùng đắt giá của hai tầng lớp giàu nghèo, đặt trong cùng một bối cảnh để nhấn mạnh sự tương phản lẫn nhau. Độc giả như bị ám ảnh bởi những cuộc sống, những mảnh đời trong từng câu chuyện và có cái nhìn đa chiều hơn về bức tranh xã hội Ai Cập đang đứng trước nhiều thách thức.

\subsection{Biểu tượng im lặng}

Sụ im lặng được tác giả sủ dụng nhu một hiệu ứng âm thanh công hương với cảm xúc của nhân vật khiến cho câu chuyện để lại nhiều ám ảnh trong lòng nguời đọc.

Đó là sự im lặng trong tác phẩm Bayt min Lahm (Ngôi nhà xác thịt).

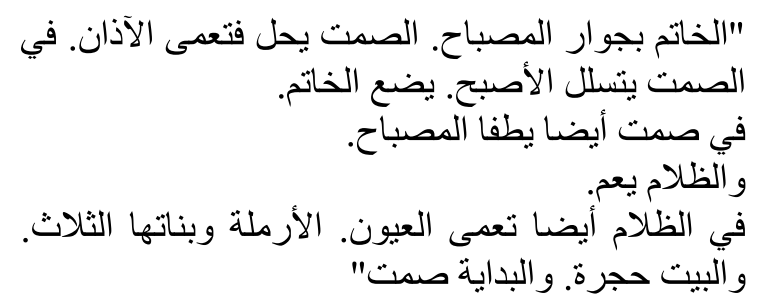

Chiếc nhẫn đặt dưới ánh đèn. Sự im lặng bao trùm khắp không gian, tai thì chẳng thể nào nhìn thấy được. Trong im lặng, ngón tay rón rén đeo chiếc nhẫn vào.

Trong im lặng, ánh sáng bị tắt phụt.

Tất cả tối đen.

Trong bóng tối, mắt cũng không thể nhìn thấy gì. Người góa phụ và ba cô con gái sống trong ngôi nhà chỉ có duy nhất một căn phòng. Sự im lặng cũng chính là sự bắt đầu.

Mở đầu câu chuyện, tác giả sử dụng ngôn ngữ đầy tính thơ, ngay lập tức mang lại cho độc giả cảm giác về nhạc điệu. Những từ có

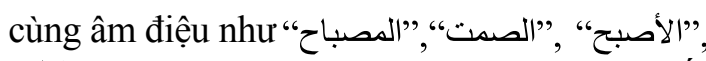
“" được lặp đi lặp lại không những tạo chất thơ mà còn có vai trò như những từ khoá rải rác khắp đoạn mở đầu. Việc sử dụng toàn bộ một cấu trúc là câu danh từ ${ }^{(2)}$ trong tiếng Ả rập, chỉ trừ câu số 3 là câu động từ ${ }^{(3)}$ góp phần vào việc liên kết chặt chẽ âm điệu, gần như tạo ra sợi dây kết nối thôi miên giữa văn bản và người đọc. Nhưng tất cả yếu tố nhạc và thơ ấy chỉ nhằm tôn lên âm thanh duy nhất - đó là sự im lặng. Sụ im lặng ban đầu xuất phát tù cảm xúc chán chuoòng của các nhân vật trước khó khăn cuộc đời.

Sự im lặng đã len lỏi vào ngôi nhà, bao vây lấy bốn mẹ con goá phụ "kể từ khi người chồng - người cha và cũng là người đàn ông duy nhất trong nhà ra đi” khiến cho không gian trở nên ngột ngạt. Cái chết của người đàn ông duy nhất trong gia đình không những làm cho họ trở nên nghèo khổ mà còn hầu như chặt

\footnotetext{
${ }^{2}$ Câu danh từ (جملة اسمية) : thuật ngữ trong ngữ pháp Ả rập, câu danh từ được bắt đầu bằng một danh từ

${ }^{3}$ Câu động từ (جملة فعلية) : thuật ngữ trong ngữ pháp Ả rập, câu động từ được bắt đầu bằng một động từ
} 
đứt cơ hội lập gia đình của các cô gái trẻ vì họ không được phép gặp gỡ đàn ông lạ mặt - điều mà ít nhất khi cha còn sống, những mối quan hệ bạn bè của ông đã tạo ra. Tưởng chừng như số phận của bốn người phụ nữ cứ thế mà trôi qua trong im lặng. Toàn bộ câu chuyện không có chi tiết nào về thế giới bên ngoài cái ngôi nhà chỉ có một phòng ấy. Họ hoàn toàn bị cách ly - sự im lặng hoàn toàn!

"Sự im lặng không bị gián đoạn bởi bất cứ điều gì ngoại trừ âm thanh của những câu Kinh Qur'ran, đã trở thành thói quen, không có gì mới lạ hay cảm giác gì."

Nhưng bề mặt của cái vòng cách ly im lặng đó lần đầu tiên đã bị rạn nứt bởi tiếng nói của vị shaykh trẻ tuổi có trách nhiệm tụng Kinh Qur 'an cho linh hồn người đã mất. Đó là người đàn ông duy nhất ghé thăm nhà họ vào mỗi Thứ Sáu hàng tuần. Ba cô con gái nhanh chóng nhận ra đây là cơ hội duy nhất giúp họ có thể tiến gần hơn với một mối hôn nhân trong tương lai. Động lực về viễn cảnh tươi sáng của họ đã cổ vũ người goá phụ trẻ, xinh đẹp tiến tới kết hôn vị shaykh trẻ tuổi bị mù đó. Và từ đây, sự im lặng đã bị phá vỡ hoàn toàn bởi tiếng cười đùa đã quay trở về với bốn người phụ nữ hay bởi tiếng hát của người đàn ông mới mẻ trong gia đình. Sự im lặng tưởng chừng như đã biến mất trong niềm hân hoan của ba cô gái trẻ hay và niềm hạnh phúc của người mẹ sau bao năm đè nén. Nhưng thực tế, nó không mất hẳn mà vẫn luôn rình rập cuộc đời của những người vốn đã sống trong sự kìm toả bấy lâu. Đó là khi người cha dượng hỏi vợ mình vì sao chiều hôm trước, khi chỉ có hai người, cô lại không đeo nhẫn cưới như mọi lần? Chỉ có cô mới hiểu được vì sao, cuộc đấu tranh tâm lý mãnh liệt diễn ra trong suy nghĩ của cô, cô muốn hét lên, muốn nổi điên! Cô có thể nói với anh đó chính là một trong ba đứa con của cô, hay cô sẽ tra hỏi ba cô gái trẻ để biết đích danh là ai. Nhưng tất cả những gì cô làm đó là im lặng! Vai trò một người mẹ - chu cấp và bảo vệ các con, vai trò làm vợ - bảo vệ danh dự của chồng đã đè sự im lặng lên cô một lần nữa. Và sự im lặng không chỉ làm thế với cô mà nó đã kiểm soát được cô con gái thứ, rồi lần lượt với cô cả, cho đến cô út. Rồi dần dần người cha dượng cũng đoán ra được sự thật đằng sau sự im lặng ây. Nhưng kể cả trong suy nghĩ, anh ta chưa bao giờ chỉ ra rõ ràng đó là sự thật gì. Chỉ nghĩ về nó cũng khiến anh mắc nghẹn! Ngay tại lúc đó, anh đã hoàn toàn bị khuất phục bởi sự im lặng.

Có thể thấy bản chất của sự im lặng đã thay đổi. Sự mỏng manh của tình huống được thực hiện ở mức độ lố bịch, vì họ đều biết rằng ngay cả một từ ngữ hay tiếng ồn cũng sẽ đủ để chứng minh thực tế tình huống của họ. Nơi ẩn náu duy nhất là tuyệt đối im lặng. Đây là những gì mà Idris gọi là loại im lặng mạnh nhất, những gì xảy ra với bất kỳ thỏa thuận nào vì sự thoả thuận như vậy sẽ đủ để phá vỡ nó.

Sụ im lặng không còn là vòng cách ly, thể hiện tâm lý chán chuờng, vô vọng của nhân vật ở đầu câu chuyện mà đã chuyển hoá thành cái vỏ để ho che chắn bản thân khỏi nhũng xúc cảm nội tâm và tránh đối mặt với sụ thật phũ phàng, khủng khiếp. Nó đã trở thành biểu tương tối cao của sư thoả thuận, thoả hiệp. Sụ im lạng giúp ho tiếp tục sống và chờ đợi một điều mới phá võ chính nó.

\subsection{Biểu tương không gian khép kín}

Một biểu tượng nũa thường lạp đi lạpp lại trong nhũng truyện ngắn của Yusuf Idris là không gian khép kín. Không gian ở đây mang cả nét nghĩa là không gian vật chất và không gian tinh thần. Ngay trong truyện Bayt min lahm (Ngôi nhà xác thịt) vừa đề cập trên, người đọc có lẽ thắc mắc vì sao cái chết của người chồng, người cha lại khiến cuộc sống của người phụ nữ lâm vào cảnh khó khăn như vậy? Nguyên nhân chính là vì những luật lệ, phong tục tập quán của xã hội đã bó hẹp, vạch ra ranh giới cho phụ nữ Muslim. Theo quy định của Islam, phụ nữ không được phép trò chuyện với đàn ông lạ mặt. Họ phải trùm 
khăn che kín đầu và không được để lộ thân thể trước đàn ông trừ những người có quan hệ ruột thịt. Đối với ba cô con gái đã đến tuổi cập kê, nhưng lại xấu xí trong truyện thì cơ hội để gặp một người đàn ông trở nên ít dần đến vô vọng. Những người đàn ông không có cớ gì để đến ngôi nhà toàn phụ nữ cả. Thật là rắc rối nếu bị bắt gặp trong hoàn cảnh đó! Cuộc sống của bốn người phụ nữ chỉ gói gọn trong ngôi nhà chỉ có một phòng. Kể cả sau khi tái hôn với người đàn ông khác, sinh hoạt của tất cả năm người vẫn trong không gian đó. Chi tiết này càng đẩy nút thắt của câu chuyện lên cao hơn, thể hiện được những cảm xúc khác biệt ở từng cá nhân về sự vui sướng, thất vọng, cám dỗ, của mỗi cá nhân, nỗi cô đơn trong mối quan hệ giữa đàn ông và phụ nữ. Cái không gian tù túng chật chội đó là minh chứng cho sụ nhẫn tâm, thờ o của xã hội đối với phụ nũ , nó là điều kiện khách quan khiến cho ho có nhũng hành động bất thuờng, đi ngược lại luân lý.

Trong nhũng sáng tác khác của Yusif Idris, không gian không bị bó hẹp, ngột ngạt nhu trong Bayt min lahm (Ngôi nhà xác thịt) nhung cũng không thoát ra khỏi một phạm vi cố định mà thuờng là làng quê Ai Cập. Bối cảnh truyện Hadithat sharaf (Một sự cố danh dụ̂) và alHaram (Cấm ky) đều diễn ra ở làng quê, không những bị giới hạn về phạm vi mà cũng giống như truyện trên, con người còn bị giới hạn bởi những phong tục tập quán khắt khe. Hadithat sharaf (Một sự cố danh dự) kể về hoàn cảnh tình ngay lý gian giữa hai người trẻ đẹp nhất trong làng. Fatima là cô gái vô cùng quyến rũ, cả người cô toát lên vẻ nữ tính nồng đượm mặc dù bị che lấp sau lớp áo choàng dài. Cô được tất cả đàn ông trong cái nông trang bé nhỏ, từ già đến trẻ đều ngưỡng mộ. "Ma lực phát ra từ lúm đồng tiền trên má khi cô cười, từ tiếng cười lăn tăn như sóng gợn của cô, mỗi âm thanh trong trẻo cô nói ra, cô biết cách ngân nga chúng và bỏ nhỏ thành từng giọt, những giọt nữ tính tinh khiết có thể làm nguội đi khao khát hừng hực của hàng chục gã đàn ông."
Trong khi đó, Gharib mặc dù rất đẹp trai và có sức hút nhưng lại không được lòng mọi người xung quanh vì tính tình lăng nhăng.

“...cậu ta còn luôn để mắt đến phụ nữ và tìm cách dụ dỗ họ, điều này khiến người dân nông trang thận trọng với Gharib. Cậu ta cũng không tôn trọng láng giềng và thậm chí còn xấc láo với mợ của mình."

Bản tính thích chinh phục của Gharib thôi thúc cậu ta tìm mọi cách tiếp cận hòng có được Fatima. Một ngày nọ, khi Fatima đi trên đường “...và̀ Gharib bất thình lình từ đâu nhảy ra. Cậu ta đưa tay túm lấy cô và kéo về phía cậu ta. Cô chống cự và gào thét cầu cứu. Ngay lập tức mọi người liền chạy tới, còn Gharib vội vã bỏ chạy."

Có lẽ ở những xã hội khác với những quy định khác, nhân vật Fatima chỉ có thể phải đối mặt với những nghi ky, gièm pha nhưng trong câu chuyện này, nếu cô không chứng minh được rằng mình còn "trong sạch" thì anh của cô sẵn sàng giết cô để bảo vệ danh dự của gia đình.

"Anh phải giết cô, giết đứa em gái chính tay anh chăm bẵm từ khi mẹ mất, giết cả Gharib - tên chó đẻ khốn khiếp anh vẫn đối xử như anh em mà rốt cuộc lại phản bội anh.

Chỉ có đổ máu mới cứu vãn được những gì đã xảy ra."

Cái vòng giam hãm suy nghĩ của con người đến từ những phong tục tập quán mà họ lâu nay tuân thủ một cách tự nhiên. Họ có thể làm tổn thương người khác để bảo toàn cái gọi là danh dự được xã hội công nhận. Chính những luật lệ, quy chuẩn đạo đức đó đã bó hẹp, kiểm soát hành vi của con người tôn thò̀ nó. Tác động của nhũng luật lệ ấy không chi trực tiếp tổn hại đến phu nũ mà nó cũng gây ra sụ đau khổ ở đàn ông. Đó là khi anh trai của Fatima quyết định giết em gái, và phải mang toàn bộ sự việc ra ánh sáng.

“Anh sẽ tự hủy hoại chính mình, hủy hoại cuộc sống của vợ và con mình trong khi mọi thứ không đáng như vậy.” 
Biểu tượng không gian bó hẹp được tác giả khắc hoạ sâu sắc hơn nữa trong truyện al-Haram (Cấm ky). Câu chuyện kể về người phụ nữ tên là Ariza bị cưỡng bức đã sát hại đứa con của mình. Cô bị điều tra và kết tội. Bầu không khí của vùng nông thôn nhỏ bé vốn đã chứa đựng những sự nghi ngờ giờ đây lại thêm căng thẳng tột độ. Với tác phẩm này, Yusuf Idris khẳng định rằng mỗi con người sinh ra trong xã hội ngay lập tức đã bị ràng buộc bởi những quy định về đạo đức và luôn bị hàng nghìn con mắt dõi theo để giám sát.

Qua biểu twợng không gian bó hẹp ấy, tác giả đặt ra câu hỏi đầy nghi ngò̀ về tính đúng đắn và phù hợp của các quy định Islam trong Haram (điều cấm ky) và Halal (được cho phép) trong xã hội hiện đại. Haram trong tiếng Ả rập có nghĩa là những điều cấm ky được đề cập đến trong các văn bản tôn giáo như Kinh Qur'an và các Sunnah ${ }^{(4)}$ bao gồm tất cả các hành động trong mọi lĩnh vực đời sống như ăn, uống, lễ nghi... Ngược lại với Haram là Halal nghĩa là những điều được cho phép. Điều này gián tiếp đề cập đến các quy định của giáo lý Islam truyền thống, thế nào là tội ác, và đôi khi những chuẩn mực, những giá trị truyền thống lại đi ngược lại với đạo đức của con người.

Biểu tượng không gian khép kín còn được nâng lên một tầm cao mới qua truyện ngắn siêu thực Al-Martaba al-muqaara (Chiếc đệm lún). Câu chuyện xoay quanh một đôi vợ chồng trẻ mới cưới trong đêm tân hôn của họ. Người chồng với tâm lý chán chường cuộc sống hiện tại đã chìm đắm trong giấc ngủ vùi, hy vọng khi thức dậy sẽ có một sự thay đổi mới. Tuy nhiên, hết lần này đến lần khác, anh tỉnh giấc vẫn thấy thế giới y như vậy nên anh quyết định ngủ tiếp và các giấc ngủ ngày càng kéo dài, từ một ngày đến một tuần rồi

4 Sunnah: bao gồm những hành động cụ thể, lời khuyên dạy hoặc cấm đoán của nhà Tiên tri Muhammad. Sunnah là nguồn tài liệu quan trọng của Islam giáo chỉ sau Kinh Qur'an. một tháng rồi năm năm. Hành động kéo dài toàn câu chuyện của anh chỉ là ngủ, đến nỗi cái đệm tân hôn của vợ chồng anh dần bị lún. Cho đến khi phần đệm xung quanh chỗ anh nằm đã vun cao, bao quanh, quấn chặt lấy co thể anh như một chiếc quan tài, đó chính là là lúc mà anh qua đời.

Trong truyện ngắn này, tác giả đã chỉ ra một tính chất khác của không gian bó hẹp, đó chính là sụ kéo dài tưởng nhu vô tận. Những điều ràng buộc của xã hội hiện đại, sự cổ hủ, không phát triển của nó được ví như cái đệm ôm lấy, quấn lấy con người và siết chặt họ cho đến khi họ không thể vùng vẫy, kiệt sức. Mở đầu truyện, cái đệm dường như vô hại hoàn toàn, nâng đỡ cơ thể cũng như khi con người vừa sinh ra trong xã hội, anh ta đã sống theo những quy định của xã hội ấy và trưởng thành. Tuy nhiên, khi con người càng phát triển, thì những luật lệ, quy chuẩn ấy cũng phải thay đổi theo. Nhưng trong câu chuyện này, chiếc đệm sau mười năm vẫn vậy, thế giới vẫn vậy, và toàn bộ những điều đó sẽ kéo lùi con người, như một cái kén mãi không bao giờ mở ra.

\subsection{Sư dụng sinh ngũ A rập Ai Cập}

Một đặc điểm nổi bật khác trong sáng tác của Yusuf Idris là ngôn ngũ được sư dụng trong các tác phẩm không phải tiếng Ả rập chuẩn mà chính là tiếng $A$ rập sinh ngũ $A i$ Cập. Tiếng Ả rập nói chung được chia thành tiếng Ả rập chuẩn (fusha) và tiếng Ả rập sinh ngữ (amiyah). Trong tiếng Ả rập chuẩn lại bao gồm tiếng Ả rập cổ điển (Classical Arabic) và tiếng Ả rập chuẩn hiện đại (Modern Standard Arabic). Tiếng Ả rập cổ điển, còn được gọi là ngôn ngữ của Kinh Qur'an, là ngôn ngữ được sử dụng trong bộ Kinh này cũng như hàng loạt văn bản viết từ thời Umayyad đến thời Abbasid (thế kỷ thứ 7-9). Tiếng Ả rập chuẩn hiện đại là hệ thống ngôn ngữ Ả rập chuẩn được Liên Hợp Quốc công nhận là một trong sáu ngôn ngữ chính của tổ chức này. Tất cả những ấn phẩm viết đều sử dụng tiếng Ả rập chuẩn hiện đại như: sách, tạp chí, báo chí, văn 
bản hành chính, giáo trình... Bên cạnh đó, những phương tiện truyền thông đại chúng đều sử dụng ngôn ngữ này. Tiếng Ả rập sinh ngữ là ngôn ngữ địa phương, có nguồn gốc từ tiếng Ả rập tuy nhiên nhiều âm tiết đã bị biến đổi tuỳ theo khu vực, thậm chí khác hoàn toàn tiếng Ả rập chuẩn hiện đại. Dù không được sử dụng để viết nhưng tiếng Ả rập sinh ngữ lại là ngôn ngữ phổ biến mà người dân sử dụng để giao tiếp trong sinh hoạt thường ngày .

Vì vậy, việc viết các tác phẩm văn học bằng tiếng Ả rập fusha là điều đương nhiên và phổ biến, được đón nhận rộng rãi ở khu vực này. Trong nhiều thế kỷ, tiếng Ả rập của $\mathrm{Ai}$ Cập amiyah đã khác biệt rất nhiều so với tiếng Ả rập chuẩn fusha, và với sự lãnh đạo TurcoCircassian của Mammelks và Muhammad Ali, sự bảo trợ về tiếng Ả rập chuẩn như là một phương tiện cho văn học bằng tiếng $\AA$ rập chuẩn. Điều này càng được duy trì mạnh mẽ bởi các cơ sở tôn giáo tại trường đại học al-Azhar để dạy Kinh Qur'an và những sách bình luận cổ điển. Sự phổ biến và tập trung trong sử dụng tiếng Ả rập chuẩn đã tạo ra thái độ kỳ thị lâu dài đối với việc viết bằng bất cứ loại sinh ngũ Ả rập nào khác ngoại trừ ngôn ngữ Ả rập chuẩn. Thêm vào đó, chủ nghĩa dân tộc đã trở thành một vấn đề gai góc cho các nhà văn Ai Cập; nếu 'quốc gia' là Ai Cập, thì nhà văn có thể viết bằng tiếng amiyyah Ả rập Ai Cập, nhưng nếu tác giả muốn tác phẩm của mình hiểu được bởi tất cả người trong khối Arabophones, anh ta sẽ phải từ bỏ cam kết thực tế và viết ra bằng tiếng fusha (Kurpershoek, 1981). Các trí thức như Yusuf al-Sharuni và Salama Musa, những người đồng cảm với cả hai nguyên nhân, cuối cùng đã lựa chọn để đứng về phía tiếng Ả rập chuẩn vì lợi ích của một tộc người Ả rập thống nhất (Brugman, 1984). Trong khi đó, nhiều nhà văn khác thực tế đã công bố những câu chuyện của họ bằng tiếng ammiyah chỉ để về sau lại lo sợ và tái xuất bản chúng bằng tiếng fusha. Đây là một vấn đề vẫn tiếp tục diễn ra và chia rẽ sự trung thành của các nhà văn ngày hôm nay.

Tuy nhiên, Yusuf Idris đã đi ngược lại quy định đó và viết những truyện ngắn của mình với các đoạn hội thoại bằng tiếng Ả rập Ai Cập - sinh ngữ Ả rập ở Ai Cập. Taha Husayn một mặt vừa khen ngợi, đánh giá cao thành quả lao động của Yusuf Idris, mặt khác thẳng thắn đưa ra lời khuyên cho nhà văn rằng nên dừng lại việc sáng tác bằng sinh ngữ nếu không muốn để tài năng bị héo mòn (Yusuf Idris, 1956). Mặc dù vấp phải sự phản đối và thái độ nghi ngờ của những nhà văn thời đó nhưng giá trị nghệ thuật mà những truyện ngắn của ông mang lại là điều không thể phủ nhận. Đặc biệt trong những tác phẩm đầu tiên của ông, trong đó sự cam kết của ông đối với chủ nghĩa hiện thực và chủ nghĩa tự nhiên đã khiến ông gắn bó chặt chẽ với "thời điểm xã hội" (theo thuật ngữ của Sasson Somekh) (Somekh, 1976). Giống như một phóng viên tại hiện trường, Idris tránh bất kỳ sự trang trí hoặc sàng lọc nào như biểu hiện đặc trưng của nhiều thế kỷ văn học Ả rập thượng lưu. Trong thực tế, các nhân vật và giọng kể chuyện của ông được pha trộn thành một thể loại văn xuôi trung lập, vô tính với một loạt các thành ngữ thông tục bằng các ngôn ngữ khác nhau, từ ngôn ngữ giao tiếp của giới tinh hoa có giáo dục (al-ammmīyah al-muthaqqafah) sang tiếng địa phương, đáng chú ý nhất là ngôn ngũ của người nông dân saidi ở vùng nông thôn Ai Cập và tiếng lóng của lớp người cùng đinh dưới đáy của Cairo (Somekh, 1984). Ngoài ra, ông còn chú ý đến ý nghĩa quan trọng trong truyền thống truyền khẩu của người $\mathrm{Ai}$ Cập mù chữ trong câu chuyện kể của họ (riwayat) và truyện cười (nukat). Trong một câu chuyện của ông, Em có phải bật đèn không Lili? (A-kān là budd yā Lìlī a tū hình thức giai thoại hài hước truyền thống (alnuktah) vào việc cấu thành một truyện ngắn. Ông còn thể hiện những nhân vật chính của mình trong quận Batiniyah (sha'bīyah) với những quán cà phê thuốc phiện và những người kinh doanh bận rộn, trao cho họ danh hiệu đáng 
nhớ "ngưòi của trò đùa" (ahl al-nukat). (Yusuf Idris, 1971). Đây là một trong những nỗ lực nổi bật nhất của ông để vô hiệu hóa tính cách xa lạ của truyện ngắn bằng cách đặt nó trong một hình thức truyền thống nổi tiếng, phổ biến (Kurpershoek, 1981).

Cả văn xuôi kể chuyện và đối thoại của ông đều có các thành ngữ và tục ngữ của người Ai Cập, và thậm chí khi viết những mẩu đối thoại bằng ngôn ngữ fusha, ông cũng kết hợp các cấu trúc thông tục để bổ sung ý nghĩa trong tiếng Ả rập Ai Cập cho những từ cổ điển. Bằng cách sử dụng sinh ngữ mà chính người $\mathrm{Ai}$ Cập nói hằng ngày, các nhân vật trong truyện được tạo nên một cách gần gũi và sinh động nhất. Somekh đã đúng khi cho rằng các đoạn hội thoại trong tác phẩm của Yusuf Idris không chỉ đơn thuần mang chức năng cung cấp thông tin, truyền đạt mà còn đậm chất bản sắc cá nhân, thậm chí được còn mang cả chức năng tường thuật (Somekh, 1975). Điều này có thể thấy trong đoạn hội thoại trích từ tác phẩm Bayt min Lahm (Ngôi nhà xác thịt) như sau:

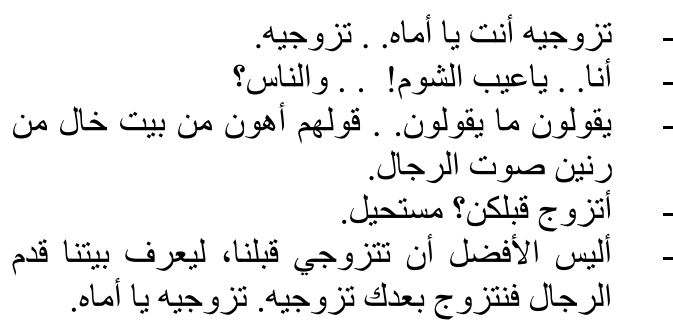

- Mẹ hãy lấy chú ây đi, mẹ ơi!

- Mẹ ư?! Thật là một sự ô nhục! Mọi người sẽ xì xào gì?

- Mọi người muốn nói gì thì kệ họ! Không gì có thể so với một ngôi nhà vắng tiếng gõ cửa của một người đàn ông!

- Mẹ tái hôn trước cả các con ư? Không thể nào!

- Đây chẳng phải là điều tốt nhất sao, mọi người sẽ biết nhà chúng ta có đàn ông, chúng con cũng sẽ có cơ hội kết hôn sau mẹ. Cưới chú ấy đi, mẹ ơi!

Phong cách ngữ pháp mới, hoàn toàn không tương thích với các tiêu chuẩn của ngữ pháp tiếng Ả rập chuẩn, thoát ra khỏi tinh thần cú pháp cổ điển tiếng Ả rập khiến cho người đọc bị ấn tượng mạnh. Bất chấp những ý kiến phê bình đối với sự đột phá này, nhiều người vẫn đón nhận sáng tác của ông, xem nó như một sự phản ánh chân thực những thay đổi đang diễn ra trong nền văn hoá Ai Cập.

\section{Kết luận}

Qua những phân tích ở trên, có thể thấy Yusuf Idris là một trong những nhà văn hiện đại nổi bật của nền văn học Ai Cập nói riêng và Ả rập nói chung. Phong cách sáng tác của ông hoàn toàn thoát ra khỏi khuôn khổ cũ kỹ trước đó, đạt đến những thay đổi đặc sắc cả về hình thức lẫn nội dung. Những tác phẩm truyện ngắn của nhà văn có thể được coi như một tuyên ngôn táo bạo về đổi mới trong góc nhìn văn học trước các vấn đề nhạy cảm đặc biệt đối với một xã hội mà Islam là tôn giáo chiếm ưu thế. Không chỉ táo bạo trong chủ đề, chủ thể sáng tác, Yusuf Idris còn mở ra lối đi mới cho văn đàn Ai Cập bằng các sáng tác sử dụng chất liệu ngôn ngữ $\mathrm{Ai}$ Cập, qua đó khẳng định bản sắc dân tộc độc đáo.

\section{Tài liệu tham khảo}

Brugman J. (1984). An Introduction to the History of Modern Arabic Literature in Egypt. Leiden: E. J. Brill.

Kurpershoek P. M (1981). The Short Stories of Yūsuf Idrīs: A Modern Egyptian Author. Leiden: E. J. Brill.

Saad el-Gabalaway (1979). The Human Bond: Notes on Youssef Idris's Short Stories. The Internatioanl Fiction Review, No.2, 137-142.

Somekh, Sasson (1976). Dunyā Yūsuf Idrīs: min khilāl aqașisish. Tal Abīb: Dār al-Nashr al-'Arabī.

Somekh, Sasson (1984). Lughat al-qișşah fì adab Yūsuf Idrīs. 'Akkā: Jāmi'at Tal Ab̄̄ô, 41-43.

Somekh, Sasson (1975). Language and Theme in the Short Storis of Yusuf Idris, Journal of Arabic Literature, Brill, 6, 89-100.

Yusuf Idris (1956). Jumhuriyyat Farahat. Dar Ruz alYusuf, Taha Husayn's introduction.

YūsufIdris (1971). Bayt min laḥm. al-Qāhirah: 'Alām al-Kutub. 


\title{
THE EGYPTIAN WRITER YUSUF IDRIS AND THE FEATURES OF HIS SHORT STORIES
}

\author{
Nguyen Thi Hong Hanh \\ Division of Arabic Language and Culture, VNU University of Languages and International Studies, \\ Pham Van Dong, Cau Giay, Hanoi, Vietnam
}

\begin{abstract}
Yusuf Idris (1927-1991) is regarded as a pioneer who lays the groundwork for the development of short stories in Egypt particularly and Arab World generally. His works have opened a new door to the literature of his country and exerted considerable influence on many young authors in the next genneration. Thus, the study of the characteristics of his short stories plays an important role in understanding the flow of modern literary development in the Arab region. This article examines four highlighted characteristics in these short stories, namely the conflict between the rich and the poor, the rural and the urban; the symbol of silence; the symbol of closed space; and the use of the Egyptian Arabic vernacular.
\end{abstract}

Keywords: Yusuf Idris, village, short stories, Egypt, symbol 